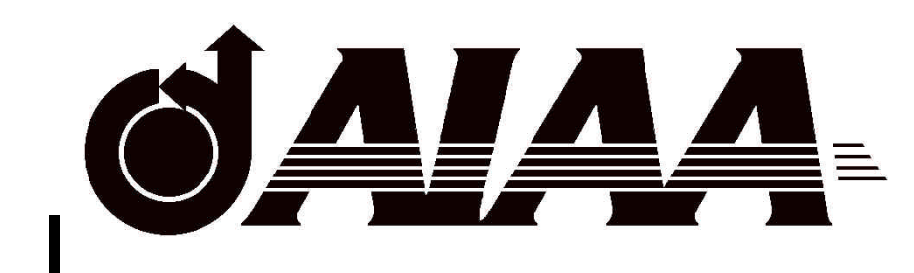

AIAA 2002-5877

A Design for a Dual-Mode Personal Vehicle

James F. Marchman III, Nanyaporn Intaratep and William H. Mason Virginia Polytechnic Institute and State University, Blacksburg, VA

2002 AIAA Aircraft Technology, Integration, and Operations Forum October 1-3, 2002 /Los Angeles, CA 


\title{
A DESIGN FOR A DUAL-MODE PERSONAL VEHICLE
}

\author{
J. F. Marchman, III*, Nanyaporn Intaratep**, W. H. Mason* \\ Aerospace \& Ocean Engineering Department \\ Virginia Tech, Blacksburg, VA 24061
}

\begin{abstract}
As part of a study of dual-mode, personal air vehicles a roadable aircraft was designed with comparable performance to modern general aviation aircraft. Of primary consideration in the design process were the dimensional limitations required for highway operation and garage storage and their impact on the wing design. A wing was proposed which consisted of an inner "box-wing" combined with outer wing sections which could be manually stowed within the inner wing during ground operation and easily attached as extensions of the inner wing for flight. An analysis was done to determine an optimum twist for the vertical sections of the box wing to produce a winglet-type thrust.
\end{abstract}

\section{Introduction}

A study was conducted to assess the feasibility of a dual-mode, personal air vehicle (essentially a roadable aircraft) to determine how constraints differ between the dual-mode concept and a CTOL general aviation aircraft, to recommend a dualmode vehicle concept, and to recommend areas where further research can contribute to the successful development of a viable vehicle design. A dual-mode vehicle with four wheels must meet all DOT and EPA safety and emission requirements for automobiles and a three wheeled vehicle is speed-restricted on the ground. Meeting the DOT and EPA requirements as well as satisfying the handling and stability needs of a highway vehicle easily results in a heavier vehicle than a comparable single mode aircraft. While this extra weight can be considerably offset with the use of modern light weight materials and construction techniques, the additional requirement for some means of folding, retracting, stowing, or towing wings and perhaps canards or tail surfaces also contributes to a heavier vehicle, especially if the transition between road and flight modes is accomplished with a motor driven automated system.

* Professor, Associate Fellow of AIAA

** Graduate Student

(C) by authors. Published by AIAA with permission.
In addition to weight, a second constraint unique to the dual mode vehicle is a result of dimensional limits in size. U. S. and EU roadway width limitations specify vehicle widths under eight feet unless a "wide load" permit is used when on the highway. Target vehicle width and height size limits were further restricted to seven feet in order to fit a home garage. This essentially means that the wing for a dual mode vehicle has as its "base" a seven foot mid section width. Any wing span beyond seven feet must be folded, retracted, or removed and stowed in some manner to fit within the selected 7' x 7' x 20' "box".

The need for a unique wing design results in two constraints for a dual-mode concept. Either a very low aspect ratio wing/fuselage design must be employed, imposing serious aerodynamic performance penalties, or a system must be developed for deployment of an "outer" wing system. In the following discussion it will be assumed that any dual mode vehicle design will probably include a two part wing which includes an "inner wing" that is permanently attached to the fuselage or vehicle body and fits within the selected seven foot maximum roadable width, plus an "outer wing" of some type that can be added to the inner wing for flight. In many past concepts, complex and heavy motor driven wing folding/retracting/stowing systems have been incorporated into the design.

If one assumes that there is indeed room for an "inner wing" of some sort within the seven foot roadable vehicle width restriction, the next task is to determine the best inner wing configuration. This essentially requires the use of a highly efficient but low aspect ratio wing design, demands which appear to contradict each other. The question becomes one of finding the best means of optimizing a very low aspect ratio wing.

One interesting concept that came to mind was that of the Custer "channel wing" [1,2], a design which can be thought of as a ducted fan using only the lower half of the duct. The original channel wing concept envisioned the semi-circular wing as having enough lift enhancement from the over- 
wing propeller to allow almost vertical takeoff or landing. While this ideal was not achievable the channel wing concept did demonstrate good short field take off performance and in recent years there has been a renewed interest in the idea.

One drawback of the channel wing is the difficulty of building the wing shape. Another is the fact that much of the low pressure developed by the propeller enhanced flow over the wing leads to forces that are not in the lift direction but are directed inward toward the axis of the channel.

A related idea is to try to enhance the flow over the low aspect ratio "inner wing" of a dual mode vehicle by mounting the plane's propeller above the wing near its trailing edge so that it enhances the flow over the wing just as the prop does on the channel wing but without the wasted side forces.

An extension of this idea is to use winglets on the inner wing, thereby forming a scoop-like channel which may enhance the propeller's influence on the upper wing flow and allow the propeller to enhance the performance of the winglets as well. It is this concept which was investigated in this study and which eventually led to the use of this "scoop wing", or low aspect ratio wing with winglets, in combination with a propeller to enhance the flow over the wing. Taking this a step further and using the winglets as vertical stabilizers, then attaching a horizontal stabilizer to the tops of the swept winglets, finally results in what is essentially a box wing configuration with an inboard propeller.

Past studies [3] have shown the box-wing to behave like a wing with a much higher aspect ratio. The swept, vertical elements connecting the upper and lower portions of the box-wing act like winglets to enhance the performance of both parts of the wing. Proper placement of a propeller at the rear of the forward (lower) component of the box wing can enhance the flow over that wing and further improve its performance.

Both experimental and analytical studies were done to get a better look at the possible performance of the "scoop wing"/winglet/box wing concept in order to assess its use on the proposed roadable vehicle.

\section{Experiments}

Tests were conducted in the Virginia Tech Stability Wind Tunnel on what was termed the "inboard winglet" model, a 30 inch span, 10 inch chord (aspect ratio 3) NACA 0012 wing with 10 inch span winglets mounted vertically and spaced 10 inches apart, creating a ten inch "scoop" into which a 10 inch diameter propeller could be placed at the center of the wing. A photo of the model in the wind tunnel is shown in Figure 1. The model was made of aluminum and instrumented with 100 pressure taps allowing the measurement of both pressure distributions using a Scanivalve system and forces using a strain gauged strut mount. The "winglets" were angled or "canted", leading edge out, to an angle of five degrees to enhance their thrust production.

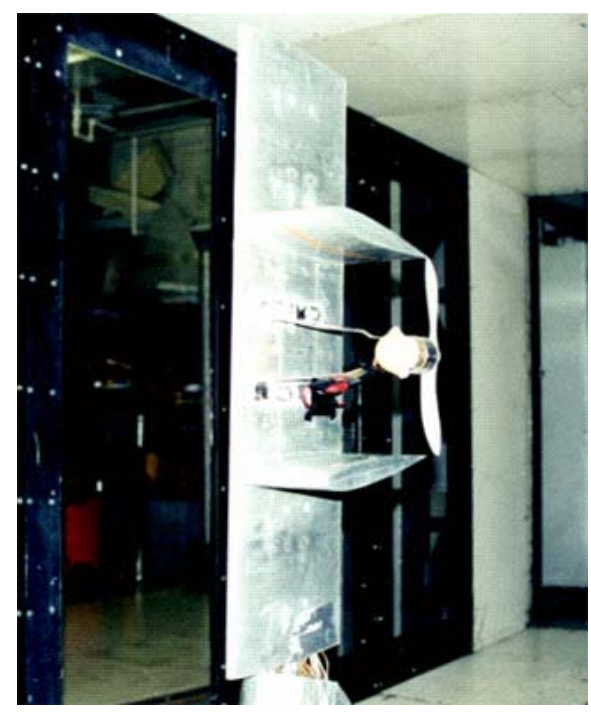

Figure 1: Inboard Winglet Model in Tunnel

Space does not permit showing most of the results of this experimental study but, Figures $2-5$ show sample pressure data for the wing at zero angle of attack with and without winglets and without the use of a propeller to enhance the flow over the wing. Figure 2 shows the pressure coefficient data taken spanwise along the wing quarter chord and Figures $3-5$ present the chordwise pressure distributions above the wing at the span centerline (Figure 3), just inboard of the right winglet (Figure 4 ) and just outboard of the right winglet (Figure 5). Figures $6-9$ show the data corresponding to Figures $2-5$ respectively with the propeller operating at a fixed power setting and at various wind tunnel speeds. 
Inboard-winglet wing $\mathbf{- q}=0.2, * 0.7, \boldsymbol{\Delta} 1.2$

Conventional wing (ref) $\square \mathrm{q}=0.2, \times 0.7, \Delta 1.2$

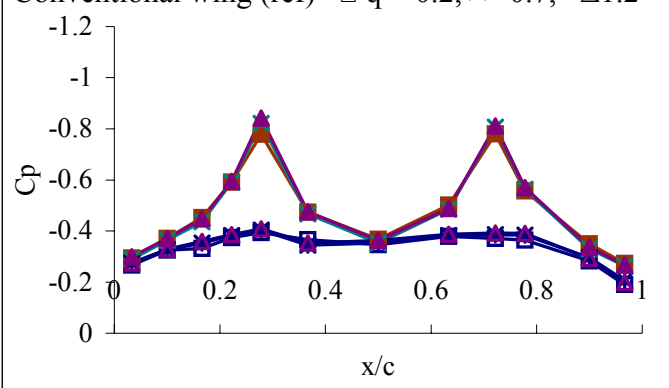

Figure 2: Spanwise Pressure Distribution Comparison at $\alpha=0$

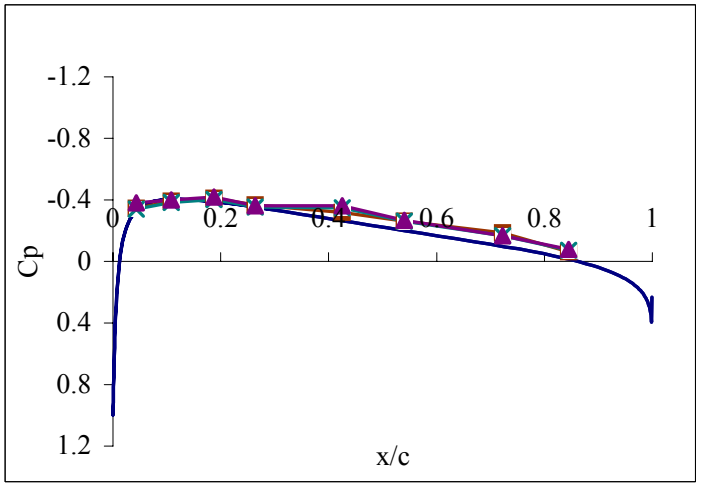

Figure 3: Center Span Chordwise Pressure Comparison to Theory at $\alpha=0$

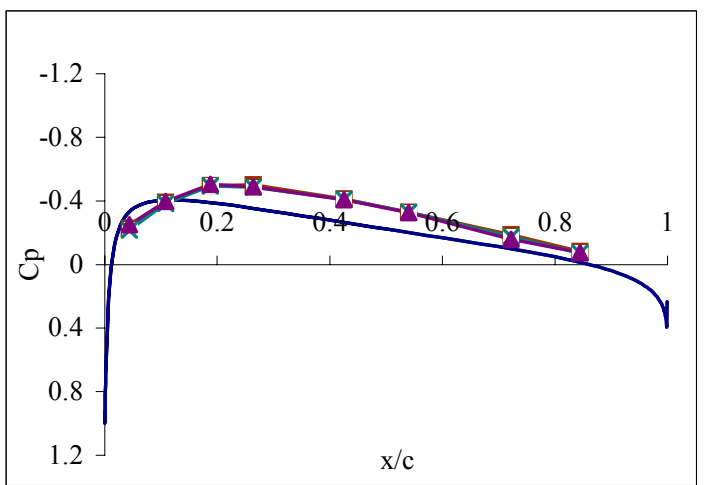

Figure 4: Chordwise Pressures Just Inboard of Winglet at $\alpha=0$

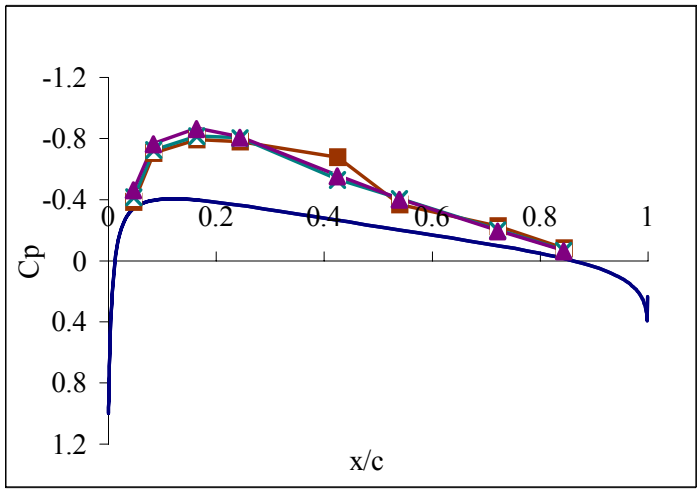

Figure 5: Chordwise Pressures Just Outboard of Winglet at $\alpha=0$

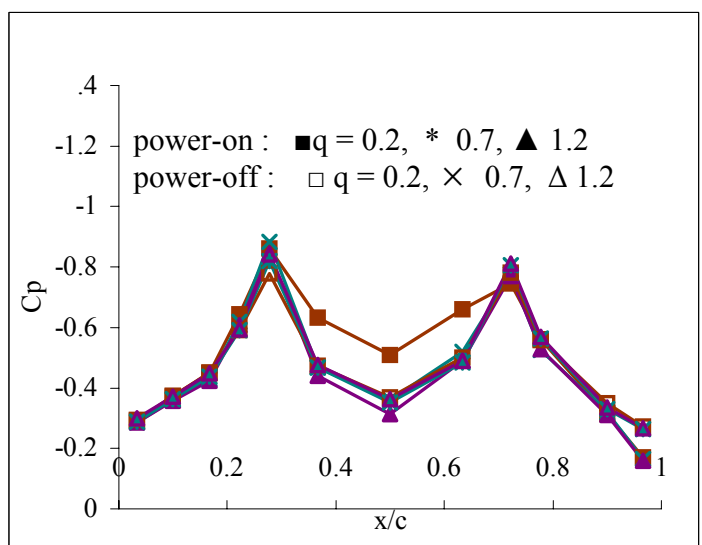

Figure 6: Power-On Spanwise Pressures

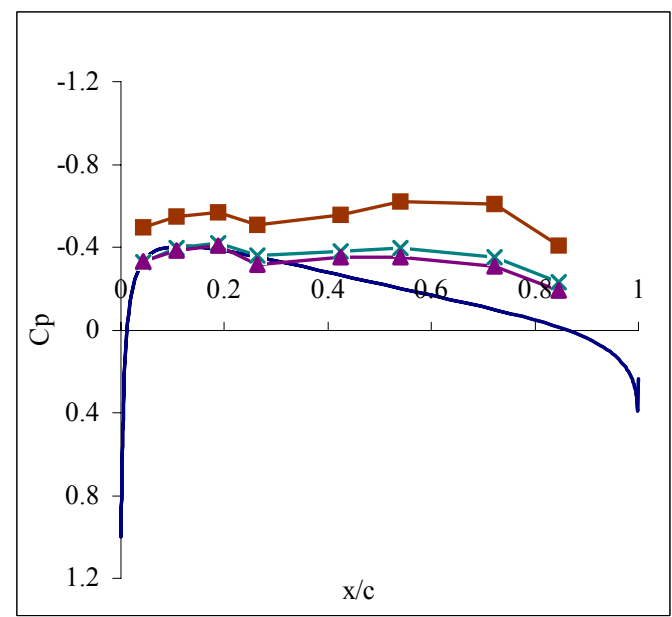

Figure 7: Power-On Centerline Chordwise Pressures at $\alpha=0$

-Theory, $\quad \mathbf{q}=0.2, \quad \mathbf{x} 0.7, \quad \boldsymbol{\Delta} 1.2$

Symbols for Figures 3-5 \& 7-9 


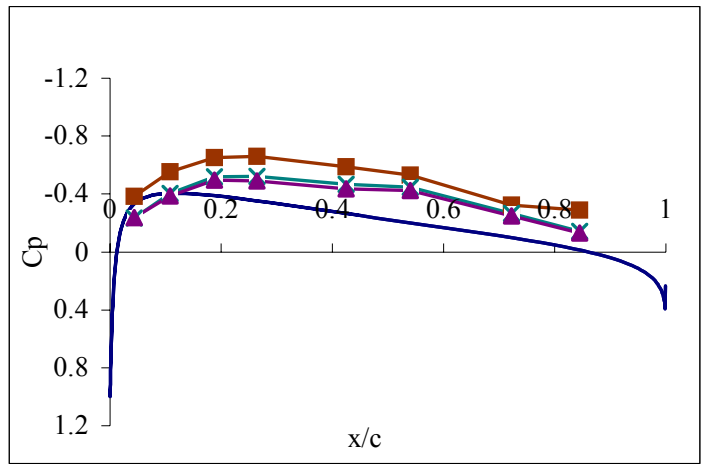

Figure 8: Power-On Chordwise Pressures Inboard of Winglet at $\alpha=0$

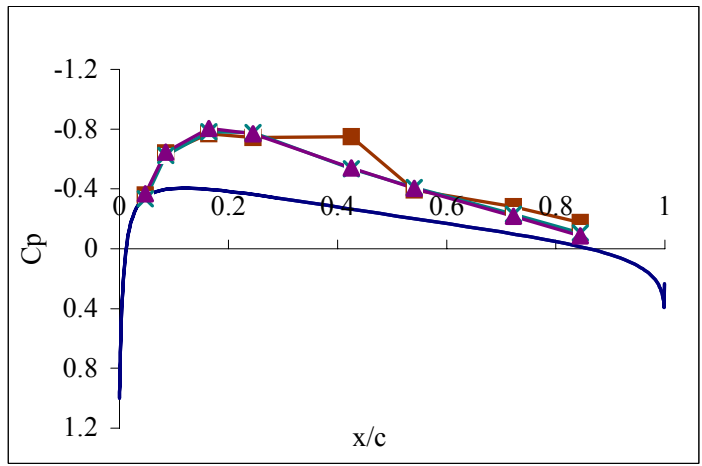

Figure 9: Power-On Chordwise Pressures Outboard of Winglet at $\alpha=0$

From this type of data the effect of both the inboard winglets on the wing itself and the added effects of the propeller operation were analyzed and the results were used to develop an analytical analysis which could be used to predict the performance of this type of wing design as the inboard wing of a dual mode vehicle. Data analysis, for example, showed that the winglets tested produced negative drag coefficients (thrust) as high as - 0.044 at a wing angle of attack of 10 degrees. This winglet thrust, along with the added lift (up to a $73 \%$ improvement) produced by both the propeller enhanced flow over the inboard wing section and by the influence of the winglets on the upper wing surface pressures was shown to substantially increase the performance of this low aspect ratio wing.

These tests were done with fixed winglets at an arbitrary five degree "cant" angle. An analysis of winglet design would suggest that the cant or twist angle of the winglet should vary with winglet span and that the optimum twist is a function of the lift produced over the wing itself. An analytical study [4] of optimum winglet twist at the take-off condition for the roadable vehicle being designed resulted in Figure 10. This analysis was based on the circulation change $(\Delta \Gamma)$ at the inner/outer wing junction and the resulting induced velocities at that location. Twist angles found were those which gave optimum thrust at various locations along the winglet span. The actual twist allowable will be limited by the stall angle of the winglet section and for the NACA 0008 inboard winglet section used in the design this limit was 14.8 degrees.

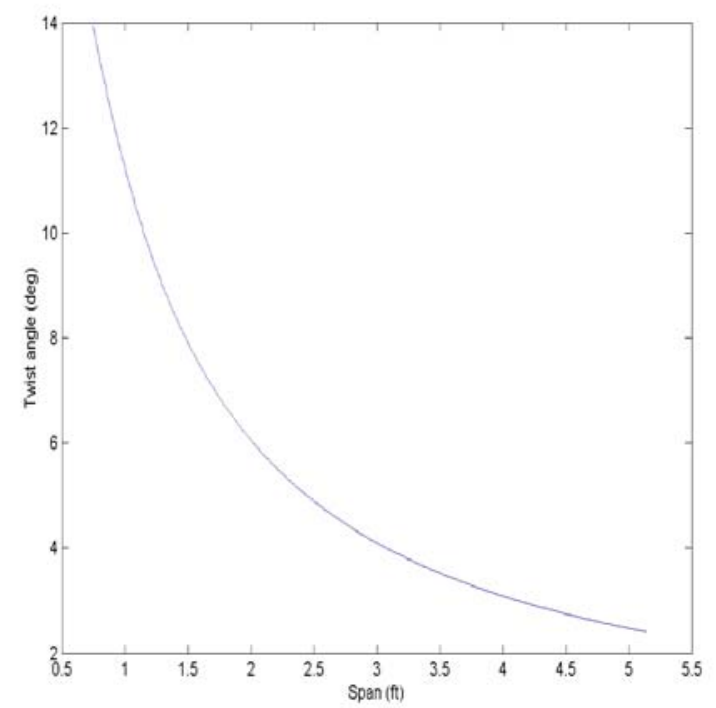

Figure 10: Recommended Winglet Twist Variation With Span

\section{Inboard/Outboard Wing Design}

Based on the experiments and analysis outlined above it was possible to design an "inboard" wing/winglet/stabilizer "box-wing" combination which would take full advantage of the vehicle's propeller-induced flow to optimize lift and minimize drag. This lift, however, was not enough for vehicle flight and an outer wing needed to be added.

Over the years there have been hundreds of concepts proposed for wings that can extend, fold and unfold, attach and detach, or otherwise be deployed for increasing wing area or span. Many of these have been part of proposals for roadable aircraft and are shown in Palmer Stiles' excellent summary of roadable aircraft patents [5]. Most current proposals for flying cars and roadable aircraft seem to rely on automated or at least semiautomated systems for deploying higher aspect 
ratio wings, stabilizers, or canards than are allowed for on-road use. There are obvious operational advantages to an automatic system in which the driver/pilot merely pushes a button or pulls a lever to change the vehicle's configuration from highway to flight mode or back. Making such a mode change without having to expose the pilot/driver to bad weather and without the need for undue physical exertion is obviously a desirable luxury; yet it is, indeed, a luxury. Such systems add complexity, operational and maintenance costs, and considerable weight to the design of any roadable aircraft, and many previously proposed systems are of questionable structural integrity.

In the original undergraduate student roadable aircraft design which preceded this study the resulting vehicle, the Pegasus [6], incorporated a screw activated extending wing design based on the patented system of Reference 7 . The "outboard" wing was made up of multiple overlapping segments which expanded like those of a collapsible backpacker's cup when a sliding screw mechanism pushed them out from their storage position within the "inboard" wing, as shown in Figure 11.

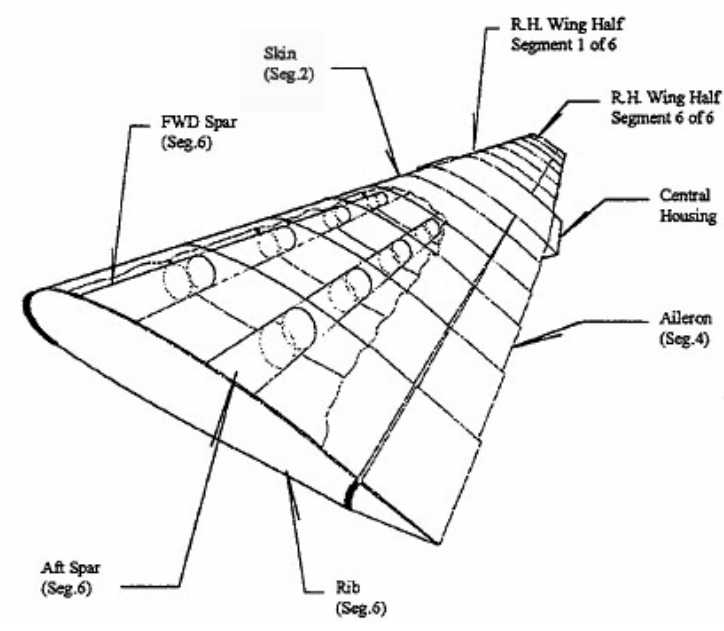

Figure 11: Telescoping Wing Design [7]

Despite the urging of our NASA sponsors for this research to retain automation in any wing/stabilizer/canard extension system, it was decided to look for a simpler and lighter weight system for outer wing deployment even though it might impose some inconvenience for the driver/pilot. The reasons for this were, we believe, both simple and obvious. First, any automated system results in much higher operational costs and weight, penalizing every aspect of the vehicle's operational performance and requiring increased annual inspection, repair, and maintenance costs as well as creating undesirable uncertainties about the reliability of the vehicle. (Anyone who has ever seen a car with automatic "pop-up" headlights going down the road with one light up and the other down is aware of the reliability problems that can be encountered in even the simplest automatic extension/retraction systems.) Second was our belief that a roadable vehicle should be just what its name implies, an airplane that can be driven on the road but which is designed primarily for flight.

We believe that it is highly unlikely for many reasons that a roadable vehicle will really ever be used as a "flying car"; i.e., a vehicle that is primarily used for the everyday commute to work or the supermarket but which can sprout wings on demand and fly over the traffic jam ahead. We believe that the future of roadable vehicles is in the ability to transform what is primarily an airplane into a road vehicle when needed; to get from the local small airport to a nearby office on a business trip or to ensure that a trip can be completed when weather ahead prevents safe flight. As such, the transformation from plane to car or back again will not be an everyday occurrence which requires automation but will be only an occasional event which does not justify the added costs and complexity and weight of the automated system.

Several criteria were established for our nonautomated system. It must be simple, allowing a one or two person task to complete either transformation. It must result in the outer wings staying with the vehicle when they were not in use. It should result in stowage of the outer wings in such a way as to minimize the possibility of damage during highway operation.

The last criteria above virtually ruled out any kind of system which folded the wings against the side of the vehicle body or towed them in a make-shift trailer, both of which have been done on some previous flying car designs. And the second one ruled out two-piece designs which left the wing or tail or some such combination at the airport when not in use.

The selected concept is shown in Figure 12. This simple design has two GAW-2 outer wings stowed inside a larger GAW-1 inner wing. The wing box for the inner wing is huge by conventional 
The selected concept is shown in Figure 12. This simple design has two GAW-2 outer wings stowed inside a larger GAW-1 inner wing. The wing box for the inner wing is huge by conventional standards and is completely open. In highway use the outer wing sections are stowed, one inserted into the open wing box "right-side-up" and the other rotated 90 degrees about a spanwise axis and inserted "upside-down". At the attachable end of both outer wing sections is a larger "box" designed to fit inside the open, inner wing box with minimal clearance and to be pinned or bolted in place in either the flight or stowed position.

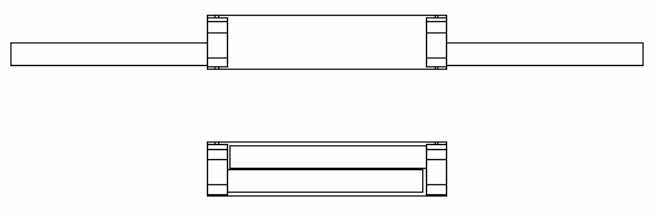

Front view

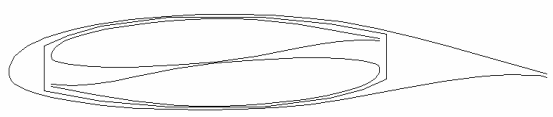

Side view

Figure 12: Stowable Wing Concept

This "stowable" wing concept is simple and light weight and would require only one to two people for outer wing deployment or stowage. The design has been assigned to the Virginia Tech Intellectual Properties Office for patent pursuit.

\section{The Evolved Design}

The final roadable aircraft design resulting from this study was essentially an extensive modification of the Pegasus design produced by a team of Virginia Tech undergraduate students [6]. Modifications included a resizing to fit NASA specifications, primarily a 7 foot maximum width, the above described re-design of the wing deployment and storage system, the optimization of the "box" wing concept based on our experimental wing testing and resulting inboard winglet analysis, and a change from a diesel engine to an engine based on the NASA GAP turboshaft design.

The resulting design, termed the "Pegasus II", is shown in Figure 13. The results of a complete aircraft mission performance analysis based on a NASA specified mission with a $400 \mathrm{~nm}$ cruise range and an 800 pound payload are shown in Table 1, including a comparison with the calculated performance of a Cessna 182 and a Cirrus SR 22 on the same mission. The table shows that all three aircraft are within the specified takeoff and landing ground roll and obstacle clearance specifications and they exceed the minimum cruise speed requirement and have stall speeds below the specified $61 \mathrm{kt}$ limit. The Pegasus II also meets the external dimension limits of 7' x 7' x 22' set for on -road operation.

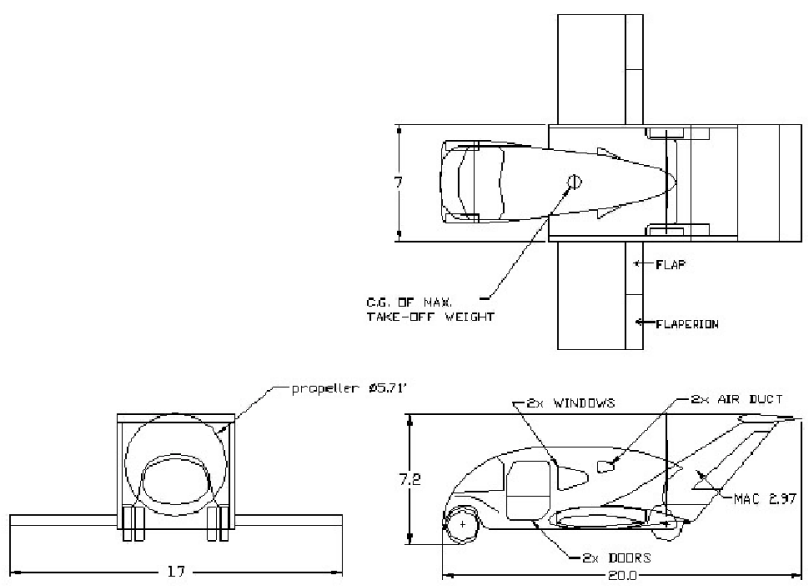

Figure 13: Pegasus II 


\begin{tabular}{|c|c|c|c|c|c|}
\hline \multicolumn{2}{|c|}{ Description } & \multirow{2}{*}{$\begin{array}{c}\text { Constraints } \\
22\end{array}$} & \multirow{2}{*}{$\begin{array}{c}\text { Pegasus II } \\
20\end{array}$} & \multirow{2}{*}{$\begin{array}{c}\text { Cessna } 182 \\
29\end{array}$} & \multirow{2}{*}{$\begin{array}{c}\text { Cirrus22 } \\
26\end{array}$} \\
\hline Dimension & Length (ft) & & & & \\
\hline & Height (ft) & 7 & 6.96 & 9.33 & 9.2 \\
\hline & Roadable width (ft) & 7 & 7 & - & - \\
\hline & Wing span (ft) & - & 17 & 36 & 38.5 \\
\hline & Wing Area $\left(\mathrm{ft}^{2}\right)$ & - & 111.5 & 174 & 144.9 \\
\hline \multicolumn{2}{|c|}{ Takeoff gross weight (lbs) } & - & 2766 & 2945 & 3285 \\
\hline \multicolumn{2}{|c|}{ Engine HP } & & 359.232 & 230 & 310 \\
\hline \multicolumn{2}{|c|}{ Fuel weight (lbs) } & - & 372 & 248 & 235 \\
\hline \multicolumn{2}{|c|}{ Wing loading $\left(\mathrm{lb} / \mathrm{ft}^{2}\right)$} & - & 24.8 & 16.9 & 22.7 \\
\hline \multicolumn{2}{|c|}{ Power loading $(\mathrm{lb} / \mathrm{hp})$} & - & 7.7 & 12.8 & 10.6 \\
\hline \multicolumn{2}{|c|}{ Takeoff ground roll (ft) } & 2000 & 474 & 501 & 786 \\
\hline \multicolumn{2}{|c|}{ Takeoff with $50 \mathrm{ft}$ clear (ft) } & 3000 & 1034 & 975 & 1380 \\
\hline \multicolumn{2}{|c|}{ Landing ground roll (ft) } & 2000 & 731 & 464 & 668 \\
\hline \multicolumn{2}{|c|}{ Landing with $50 \mathrm{ft}$ clear (ft) } & 3000 & 1732 & 1096 & 1451 \\
\hline \multicolumn{2}{|c|}{ Service ceiling (ft) } & - & 18378 & 25416 & 30688 \\
\hline \multicolumn{2}{|c|}{ Absolute ceiling (ft) } & - & 19337 & 27589 & 32769 \\
\hline \multicolumn{2}{|c|}{ Max speed at $80 \% \mathrm{HP}(\mathrm{kts})$} & 100 & 180 & 137 & 185 \\
\hline \multicolumn{2}{|c|}{ Stall speed w/flap at SL (kts) } & 61 & 60 & 48 & 58 \\
\hline \multicolumn{2}{|c|}{ Stall speed clean at cruise (kts) } & - & 71 & 61 & 77 \\
\hline \multicolumn{2}{|c|}{ Max rate of climb (fpm) } & - & 2254 & 1522 & 2002 \\
\hline
\end{tabular}

Table 1: Vehicle Performance Comparison 
There are many aspects of the Pegasus II design that are carried over from the original Pegasus design [6] and are not discussed in this paper. These include the design for variable height front and rear wheels to allow rotation on takeoff and the complete assessment of the vehicle's ability to meet both US and EU highway operational regulations. Also covered in Reference 8 was an analysis of the propeller noise, a particular concern with pusher prop designs, and the design's ability to meet proposed strict noise standards

\section{Conclusions}

Based on our studies we believe that the Pegasus II represents a feasible design for a roadable aircraft. We believe that the "box-wing" configuration, which was earlier identified by Kroo and McMasters [3] as an optimum way to gain spanwise efficiency within a set wing span, can be further improved by twisting the vertical segments of the box wing for optimum winglet performance and be used to create the most effective low aspect ratio inner wing possible for a roadable vehicle.

We have also proposed a unique and simple design for a three piece expandable wing which will allow easy, manual conversion from highway to flight mode or back without the need of expensive, complicated, or heavy automated devices. While a totally automated conversion between flight and road vehicle operational modes might be desirable or even necessary if one envisions a vehicle that is continually being transformed from one mode to the other, we believe that this will not be the normal operational pattern for a successful roadable vehicle. We see the primary mission for a roadable vehicle not as a means of everyday, all purpose, local transportation, but as a general aviation airplane with the added capability of being able to operate on the highway when needed, thus, not requiring regular, automated change-over capability. Given the performance penalties paid for the extra weight and the operational cost penalties inherent in any automated conversion system we see the simplicity of the proposed wing stowage system as a strong selling point in a roadable aircraft design.

It is obvious that the simplest design for any "outer" folding, retracting, stowing wing will be one which requires a minimum number of transition actions; i.e., a single fold, a single retracting segment. If automation of transition is sought this will result in the lowest weight design. However, the lifetime cost of wing transition automation must be evaluated since a nonautomated transition will provide significant weight savings. Given the small fraction of total vehicle use time involved in the road/flight mode transition process and the penalties that the extra weight of an automated transition system would impose on the vehicle's flight mode performance, a manual transition concept design was selected for the outer wing. In this innovative design the outer sections of wing are manually "stowed" in the inner wing box in a manner which has apparently not been previously proposed.

The use of the redesigned inboard wing configuration and the light weight and simple wing conversion system has resulted in a design which should compare very favorably to both the successful older design GA aircraft represented by the Cessna 182 and to the most modern GA vehicles represented by the Cirrus SR-22. To do this greater engine power is needed than use by either of these commercially available aircraft. This is due to the added drag of the low aspect ratio wings on the Pegasus II and to the higher profile drag of an automobile configured vehicle body. Fortunately, the new GAP engine designs promise to provide the needed power without increasing vehicle weight.

\section{Acknowledgments}

The authors would like to acknowledge the support of NASA Langley Research Center and NASA Grant NAG1-01100 in funding this study. We would also like to thank the students at Virginia Tech and at Loughborough University (UK) for their creation of the original Pegasus design. We also thank Eugene Skelton for his contributions to the project.

\section{References:}

1. Young, D. W., "Tests of a 1/3-Scale Powered Model of the Custer channel Shaped Wing", U. S. Army Air Forces Technical Report No. 5142, 1944

2. Young, D. W., "Tests of Two Custer Channel Wings Having a Diameter of 37.2 Inches and Lengths of 43 and 17.5 Inches", U. S. Army Air Forces Technical Report No. 5568, 1947

3. Kroo, Llan, and McMasters, John, "Highly Non-Planar Lifting Systems", Transportation Beyond 2000, NASA 
Conference Publication 10184, pp 331 370, February 1996

4. Intaratep, Nanyaporn, "The Investigation of an Inboard Winglet Application to a Roadable Aircraft", Masters Thesis, Aerospace \& Ocean Engineering Dept., Virginia Tech, Blacksburg, VA, June 2002

5. Stiles, Palmer, Roadable Aircraft: From Wheels to Wings, Custom Creativity, Inc. Melbourne, FL, August 1994

6. Gassler, Rebecca, et.al., "Pegasus, A Report to the AGATE NASA/FAA General Aviation Design Competition", Aerospace and Ocean Engineering, Virginia Tech, Blacksburg, VA, May 2000

7. Czajkowski, M., Clausen, G., and Sarh, B., "Telescopic Wing of an Advanced Flying Automobile, AIAA Paper No. 975602, 1997

8. Marchman, J. F., Intaratep, N, Skelton, C. E., Mason, W. H., "An Investigation of CTOL Dual-Mode PAVE Concepts", NASA Grant NAG-1-01100, Virginia Tech AOE Report 276, January 2002 